\title{
The Need for Digital Learning Environments
}

\author{
Seppo Sirkemaa \\ Turku School of Economics at the University of Turku \\ Turku, Finland \\ Heidi Varpelaide \\ Satakunta University of Applied Sciences \\ Pori, Finland
}

\begin{abstract}
Traditional lecturing and classroom-based education is challenged by learning environments which are relying on information technology. Today there are plenty of new tools and applications that can empower the learning process. This study looks at the digital learning environment of a university, the use of technologies and applications in learning. where students are working in groups. The results of a questionnaire indicate that university's learning platform and social media applications are both used in learning. While the learning platform is used for material storage and general information delivery, social media applications are used in interaction between students, in ways defined by students. For further research, including students from other universities and teaching staff would give a wider perspective on directions where the learning platform should be developed.
\end{abstract}

Keywords: Learning; learning environment; group work; technology.

\section{Introduction}

Technology and networks are widely being used for all kinds of purposes. Individuals, companies and organizations in different sizes and industries use technology for various purposes, work, leisure and interaction. Also in education things are moving towards digitalization. For example, learning material, exercises and interaction between students and teachers take advantage of computers and technology. Learning can take place also outside traditional classroom environment where students are expected to be active learners. Learning is more than attending lectures or reading books to exam. Interactive elements, group assignments and learning in these situations are increasingly important elements in modern learning environments (Leonard \& Leonard, 2001; Laal \& Laal, 2012). 
The educators and educational institutes have several different digital tools and environments for learning. Ideally, the goal is to develop a learning environment that supports learners in best possible way. The key issue in learning is interaction between teachers, students and student groups - and this interaction should be empowered with information technology (Jonassen, 2000). The applications and methods for group-based learning are here in focus - what is the reality in group based learning today.

\section{Towards Digital Technologies}

In increasingly technical environment it is natural to expect technology, information systems and networking also in education (Jonassen et al., 2008). Traditional lecturing in a classroom is still fine, and attending a good lecture can be an eye-opening experience. However, students expect also flexibility, ways to combine studying and working (Facer, 2011). Here modern technology has plenty of potential (Lim \& Chai, 2008). The term modern learning environment is used in this context, to refer to learning environments and platforms, together with technologies and systems that are used in different learning situations to educational purposes.

Today flexibility is important in education. For the student, educational arrangements should be flexible so that it would be possible at each student's own pace whenever appropriate to the student. With technology studying should also be possible from a distance, without the need to attend university campus daily. Education, curriculum and courses should be organized so that they meet today's student's needs, where anywhere and anytime are key issues. It challenges to thinking differently, earlier it was expected that students attend lectures when it is appropriate time for educators to organize them, now education should be provided to learners so that it fits their schedules. The whole educational paradigm is changing, the focus will be on students instead of educational institutions or lecturers (Dooley et al., 2016).

Information systems and technology may support learning in different ways (Algozzine \& Anderson, 2007). It offers applications for information delivery, and in the most sophisticated forms it is a cognitive tool (Reeves \& Laffey, 1999). Here information delivery refers to situations where technology is used primarily in accessing and delivering information which is stored in digital format. University email systems or digital platforms that are intended for sharing learning material are examples of these applications. Overall, these systems and technologies are relatively robust and straightforward to use. Once they are up and running they do what they are intended to do, whether it is delivering an email notification or retrieving search results from a database search. However, not all systems are as straightforward. For example, digital learning platforms may be used for various purposes, and in many ways. They can be used as a repository of learning material on some courses, and in others they provide tools for group work. Also, video-based material, streaming of lectures, video tutorials or video-chats can be available. In most cases it is about the faculty, discipline, and most of all individual lecturers and faculty members who decide how digital tools are being used in different phases of the 
curriculum (Pani et al., 2015). On the other hand, the selection of tools reflects the demands of the students, or simply what has been agreed in each course, assignment, seminar or between the students and educators. The agreements may be official, university-level policies, or conventions about working methods in a certain course, as an example. It is also possible and likely, that students decide by themselves unofficially what technologies and applications they use, to work on a given group assignment.

The role of technology can vary greatly in different learning situations and learning environments (Jonassen et al., 2008; Wagner et al., 2008). It is quite possible to find courses where teaching and learning are relatively traditional. Even though 'technology and computer -free' education is still possible in most cases the involvement of technology can be significant, even in teaching situations which are in first look not taking advantage of technology. It is a matter of resources and efficiency - it is simply more efficient to prepare learning material and exercises with computers, and run administrative tasks with information systems, faster and with smaller resources. Teaching can be based on attendance in a classroom, lecture-based learning, exercises and exams within traditional fashion. However, it might be argued that in even these cases there are some level information systems, at least in administrative arrangements, planning of schedules, student administration ... etc. There can also be courses and learning contents that are completely digital. In these cases, learning material available is in digital format and accessible with computers. Learning can take place online, anywhere and anytime without the need to attend lectures. However, in many cases there are courses which have elements of both traditional learning and online education. This is referred to as "mixed mode" education (Jonassen, 2000; Hakkarainen, 2009).

\section{Technology and Learning}

There is significant interest among higher education institutes in combining technology in the learning process (Lim et al., 2014). It can be argued if technology automatically has a positive impact on learning. It may even be that in some cases the results can be even negative. As an example, most have experienced difficulties with technology not working as expected, system failures and unexpected problems with computer systems. Both teachers and students should have experience with technology, and know how to use tools and systems to successfully manage modern learning environments (Burns, 2013).

Technology can be used in many ways, and in educational context technology and information systems should be used in a way that they bring added value, help, motivate and empower the learning process. Technology should have a positive impact, but not have a too central, dominating role in teaching situations (Gros, 2002). It is an underlying element, learning platform that enables different activities and processes in learning. The role of technology becomes visible when there is a breakdown, malfunction or technical error that stops activities or makes teaching and learning impossible. As a result, it is 
important to develop system that are robust and reliable, and function as smoothly and possible.

In general, educational information systems and technologies have typically following characteristics (Gros, 2002):

- Platform for activities: technology and information systems can be used in accessing content, but also in different learning activities (such as group-work)

- $\quad$ Need for realism: a great deal of importance is placed on creating an environment that is as realistic as possible

- $\quad$ Tool for learning: Technology is understood as a tool that mediates learning

- $\quad$ Time and space; learning environments should be analysed within the context of social change and evolution. Today many stores are open almost $24 / 7$, and one can do shopping with computers in webstores whenever one wishes. It is understandable to expect the same from education.

Modern learning environments are based on a learning paradigm that understands learning as an active and constructive process (Jonassen, 2000; Harasim, 2012). In this view students are expected to be active learners, to use technology to access and process data to meaningful information. Teachers are not seen as traditional lecturers which present material already written in books, instead their role is to act as mentors and motivators in students learning process. Interaction with fellow students has also an important part in learning (Vass \& Littleton, 2010; Laal \& Laal, 2012). The possibilities that technology brings to interaction and group work are interesting, as one is does not necessarily be in a certain location at a certain time, interaction can also take place from a distance.

The learning environments should take advantage of technology so that it supports the learning processes in the best possible way (Tomlinson, 2003). We use the term adaptation in this context (Brusilovsky, 2001). There are two types of adaptation here, adaptation to the user device and adaptation to user's behaviour.

Adaptation to user device refers to the range of technologies that user's may use when using the systems (Brusilovsky, 2001). For example, how can learning materials be accessed and what applications may be used when working on exercises. This type of adaptability to is known as portability, and it becomes visible in the flexibility to use different computer technologies, user terminals and operating systems. As the number of different terminal devices is large, there is a need to increase portability so that systems can be accessed with many different user devices. The material in a learning environment could be accessed with a desktop computer, or a smartphone, even can even though the screen sizes and input devices would be different. One approach how heterogenous user devices can be used in web-based learning environments is to prepare the learning material using XML-standard (Wehner \& Lorz, 2001; Hummel et al., 
2004). It allows scaling of content to a variety of terminal devices, thus maximizing the flexibility to use different user devices.

The other type of adaptation, adaptation to user's behaviour is connected to expectations, user acceptance and perceived ease of use (Brusilovsky, 2001). They are result of user's earlier experiences with technologies, and with future expectations. Furthermore, people have different attitudes towards information systems and technologies, some are eager to adapt new technologies while others can be more sceptical, resist change or have negative attitudes towards technological innovations. As a result, systems developers work to create best possible user experience for each type of user. It can be result of giving different kinds of options for use, like regular or experienced user interface. User's behaviour can also be analysed, and so the system can better be tailored for different user types, and content customized for users (Rich, 1998). The level of adaptation can change over time as users gain experience and learners use the system better for their purposes.

Learning environments should be tailored to differently skilled learners. Those who are experienced technology users may find some systems easy and straightforward. On the other hand, as some are not similarly technologically oriented the user may feel lost or otherwise experience the environment confusing. This can be quite confusing, as some learners may find the environment easy to use while some others think it is difficult to use. The idea of working with mainly digital learning material, online environment may be overwhelming to some learners. Adapting the learning environment to different learners may be one of the greatest challenges for developers of learning environments (Raskin, 2000).

In educational context, adaptation can be viewed from the perspective of technology and its role in teaching and learning. If we look at teaching staff there is another dimension to adaptation. It is not only working with computers and networks; digital learning environments call for learning material in digital format. Converting existing into files, and uploading them to a learning environment is often seen as the most important issue when creating a modern learning environment. The pedagogical aspects may remain unchanged, or there is no discussion about what should and could change in teaching practices in digital learning environments. For example, interaction among students has significant learning potential. It would be ideal if learners had possible to learn in a way that best fits their needs and leaning styles. Possibility to access learning material from a distance, interaction and groupwork should be made possible. Overall, if technology makes it possible to be a part of learning community, even when the learner is not at campus daily, this can have a significant positive impact. Modern learning environments have important role here as they can be both a platform for learning content and area for interaction between learners and teachers (Dooley et al., 2016).

Development of modern learning environments makes it possible to rethink the roles of students and teaching staff (Reeves \& Laffey, 1999; Tomlinson, 2003). 
Ideally, when technology is being involved in learning the goal should be that the learning experience would be better than in traditional education. Uploading material to a digital learning platform is not enough. New learning environments allow pedagogical changes, moving from lecturing towards tutoring and mentoring (Jonassen et al., 2008). Learners should be active and have the ability to study and work in a virtual environment which sometimes calls for determination to overcome technical problems.

\section{Skills needed in modern learning environments}

In general, teachers should be skilled in using computers (Burns, 2013). They should understand the limitations of technology, what is possible and what cannot be done with existing resources. For example, in mobile technologies there are several issues that can make the using mobile terminal devices complicated (like relatively small screen and keyboard, low bandwidth or short battery-life). Technical skills and familiarity with the digital systems are required, to master learning in the learning environment (White et al., 2010; Moussa-Inaty, 2017). Teaching staff needs to manage computers and technology in different stages:

- $\quad$ Before: Teachers should know how to use different applications when preparing material to digital learning environment.

- $\quad$ During teaching: in various teaching situations, lectures, tutoring sessions and group-work situations there are several technologies and applications that the teacher needs to master, typically in a stressful situation in front of a live audience.

- $\quad$ After: later when replying student questions, evaluating exercises and grading students.

All faculty and staff members in teaching and administrative positions need to have good IT skills, and there should be guidance available and a support when needed. The use of technology is widespread in student administration, from course descriptions, timetable management, learning platforms and interaction are based heavily on computers, networks and the information systems infrastructures. Learning environments are challenging also for learners. The whole approach to learning has changed. Today it is an active process where students must study, seek and process information from various sources, and process it with different technological tools, applications and systems. As a result, skills in information technology have an important role in learning environments (Burns, 2013).

To summarize, the roles of students and teachers is changing in modern learning environments. Here teaching material is in digital format so that students can access it with their own devices independently of their geographical location or time of day. Interaction, discussion and feedback between teachers and students relies on networks. Technology is in a key role in studying - it is hardly possible to study without using computers and information technology. Therefore, students must have the skills to use technology. Otherwise it may be overwhelming trying to manage in the digital environment. For example, there are numerous settings that must be set to access learning environment from a 
mobile, portable computer terminal. If you have little experience with computers, and have no fellow students or friends that could help you are in trouble. It is also important to provide help and user support. Conditions for digital learning should be addressed in developing the learning environment, so that technologies and applications are straightforward to use (Tomlinson, 2003).

\section{Towards Group Based Learning}

Learning is an individual, constructive process where new information is being mapped and structured based on learner's earlier experience and knowledge base (Harasim, 2012). However, there is also an interactive dimension to learning (Vass \& Littleton, 2010). Learning has collaborative elements, being part of a community and learning as a member of a group has an important role in the learning process (Leonard \& Leonard, 2001). The term collaborative learning refers to a method in which learners at various performance levels work together in small groups toward a common goal (Laal \& Laal, 2012). Creating a learning environment is not a technological challenge alone, working together with students coming from different backgrounds requires lot of development activities that call for creating practices that connect learners and faculty staff, so that the learning process can be empowered. In some universities, schools and programs there has been significant emphasis on development of the digital learning environment and processes, to reach learning goals (Pani et al, 2015).

Technology has significant potential in connecting people together (Lim \& Chai, 2008). It is a tool that helps in meeting people, exchanging ideas between students and student groups. Here we argue that technology can empower communication between teachers and students. There are several technologies and applications available for group based learning. These can be categorized into two main categories: firstly, tools that are part of learning environment and secondly, other mainly social media applications that are generally available for interaction and information sharing, but may be suitable for learning purposes. Digital learning environments have numerous built-in applications for interaction. In a typical case students and teachers can easily send messages inside the learning platform, without need to go external email-system to do this. The downside is that one does not necessarily notice that there is a pending message if you don't log in to learning platform daily. Currently learning platforms do not have applications for smartphones and so students and teachers do not see incoming messages in similar way as in standard emails which practically all connect to smartphones.

It is common that digital learning environments allow group activities (Vass \& Littleton, 2010). For example, Moodle has a forum activity module which enables learners to have asynchronous discussions. This refers to discussions that take place over a longer period, all participants do not need to be online at the same time. There are several types of discussion forums to choose from. In a standard, open forum a new discussion topic can be started at any time. However, there are also more limited forums. It is possible to limit posts so that each student can post only one discussion, or to provide a question and answer forum where student must first post before being able to view other students' 
posts. Posts can be evaluated by peers, in this context by teachers or students. Another interesting module is workshop. It allows collection and review of assignments, and evaluation of assignments. Students may upload any digital content, such as text-based documents or spreadsheets and can also type text directly into a text-field in the module. The evaluations can be summed to form a grade which is then recorded as course degree. If we look at the modules and applications that are part of learning environments it is noteworthy that they integrate well to the learning platform. This means that whatever the activity might be they can be accessed and evaluated also later from the learning platform, with no need to separately accessing other systems.

There are several applications that might be suitable for group working purposes, interaction between two or more students. For example, Facebook might be used for this purpose. It allows creation of public groups that are generally available, or private groups (for example for a group of students working on an exercise). When connecting to others in the same group, WhatsApp might be a good alternative because it's easy and intuitive interface. Facebook and WhatsApp are both available directly from a smartphone, which allows connectivity anytime and anywhere (Quan-Haase \& Young, 2010; Madge et al., 2009).

\section{Empirical Evidence: Methodology}

This research focuses on digital learning environment, the technologies and applications used for learning purposes. The empirical part of the study was explorative, with the emphasis on finding how students study, and what technologies and applications they use. There are both quantitative elements, but most important findings are based on qualitative, open-ended questions in the questionnaire. The research sample consists of students, who answered through a web-questionnaire. (Mann, 2006; Creswell, 2012)

The empirical evidence is from University of Applied Sciences in Satakunta, Finland. Empirical study was carried out at this university, among students who participated in a course that is about digital technologies in organizations. The course involved group assignments, exchanging ideas and working together in smaller groups. Groups consisted of 3-5 persons, and there were several groups. The web-based questionnaire had questions that were to be answered numerically (for example, in how many courses is there interaction in digital form), but there were also open questions where the student could write his or her ideas freely. Here the students were asked what technologies and systems they use for studying, and how they do group assignments.

Webropol was used as an online tool for gathering data, as it is widely used at the case university, and it provides anonymity for the person answering the questionnaire. The number of students participating was 157 (n=157), from two different courses with similar content arranged in different teaching periods, one after another. The timeline for gathering answers was around 2-3 weeks during Spring 2018. 
The focus of the questions was not to look at practices in this or any other individual course, instead to reflect the practices, technologies in the learning environment, and courses in general. Students were asked to answer the questions, with the idea of developing teaching practices at the university anonymously. Time for answering the questionnaire, and background motivation for the questionnaire took place during a course, where the person in charge told about the study and asked students to fill the questionnaire.

\section{Discussing empirical findings: Different courses, different methods}

The findings indicate that learning environments have different roles, mainly depending on courses and lecturers. Generally, there are courses and lecturers which use digital learning environments mainly as storage of learning material. It is common to have exercises available from the learning environment, and channel feedback on exercises through the course area, also in the learning environment. In a typical university course, the electronic learning platforms are Moodle, and for interactive conferencing WebEx. In the case university these systems are officially supported, and used as a backbone for teaching activities.

Figure 1 summarizes digital elements in the case university. The meaning of the terms (like what is meant by interaction) were explained in the questionnaire. Number of courses indicates the number of courses students take during a semester (fall-spring). Here bars indicate lowest (blue), highest (red), and median (green) number of courses. When looking at the number of courses and "digitalization" which refers to number of courses that have digital elements, it is found that most of the courses are digital, as seen by students. The following bars indicate that digitalization is relates to having a digital platform (refers to use of Moodle in the courses), file storage (learning platform contains learning material such as slides) or that the course has interactive, digital elements (WebEx or other similar applications). Furthermore, studying the results, reveals that there are still also courses that have no digital content.

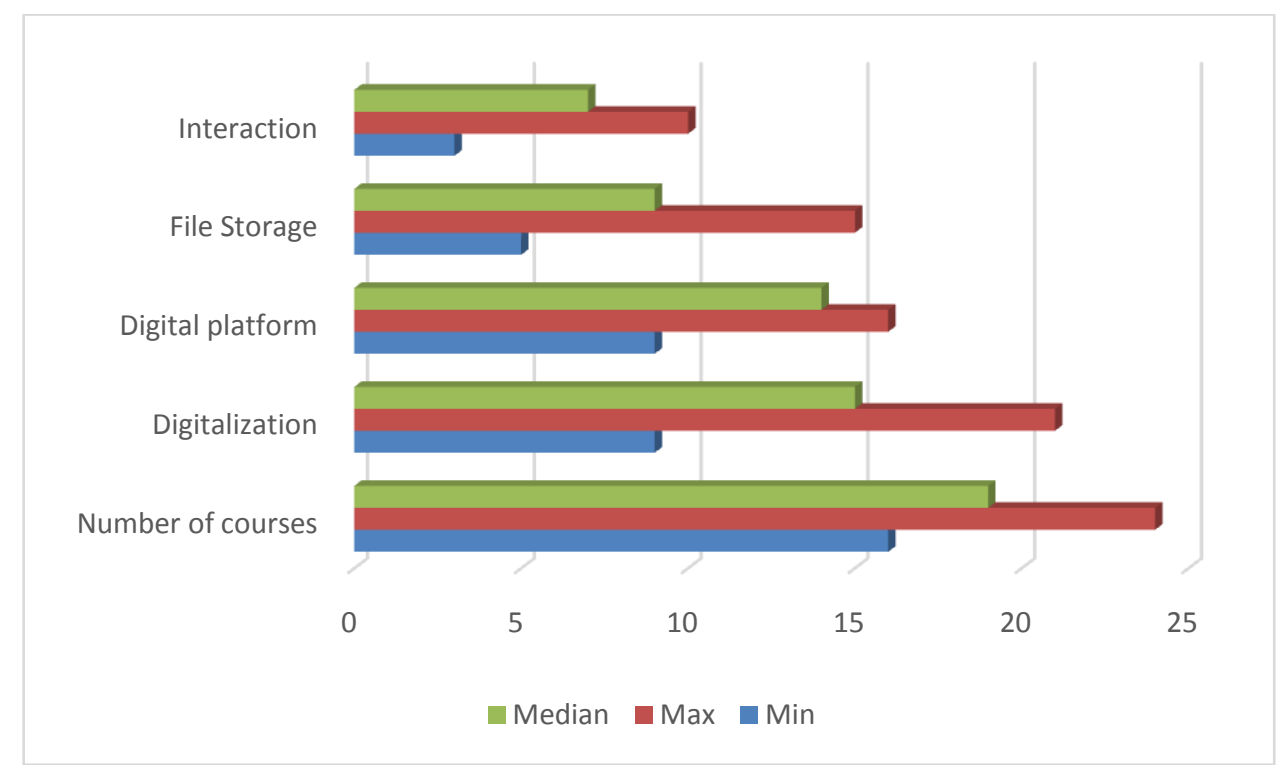

Figure 1: Digital elements in learning platform 
It is common to have learning material, information on learning goals, upcoming events or schedule in course area of the learning platform. Altogether, this type of content is relatively normal in all courses that are in digital learning environment. Student comments "All courses [that use Moodle] have course goals, and material in Moodle, at least in some degree". There were no student comments of any alternative ways of using the learning environment, so the assumption is that Moodle-course contain course material and information.

When it comes to discussion forums, group work areas and other more interaction oriented modules there is significantly more variety. Student writes "In the beginning of the courses we get into groups and discuss how we are going to work, using what systems. For more interactive discussions we use WebEx-rooms, and for text-based interaction is WhatsApp a very popular choice today. Typically, files are in OneDrive and we edit them with Word". Another student notion remarks "The lecturer did not say anything about interactive applications" while one student wrote "She told us that results of group exercises will be discussed with WebEx". As a summary, it seems that some lecturers are using interactive applications whereas others have not yet had courage to start exploring their possibilities (Figure 1). The decision of using interactive applications has in some cases been given to students to decide.

\section{Using the learning environment and social media applications}

The results indicate that using other interactive applications than those available in the official learning environment varies (Figure 2). Teachers use Moodle for providing course-related information, for example by placing it in News-area in Moodle or sending messages via Moodle. Student writes "What I have seen information is in the Moodle-course, and information on recent changes is in Newsarea". In some cases lecturers may send course-related email directly to students, using standard email of the university. However, students prefer using also social media applications like Facebook or WhatsApp. This is something that students decide by themselves, and it is often a group-based decision. Teachers promote the use of Moodle and WebEx, but are not actively motivating students to use WhatsApp, for example. It is likely that the explanation is that only those applications and systems that are officially supported, will be used in teaching situations, other applications are not promoted as user support is not available from the university. This does not prevent students from using these applications in working together. It is noteworthy, that students do not necessarily connect with lecturers using Facebook or other similar applications. When working with assignments the "fastest way to change ideas is messaging with WhatsApp" as written by a student. Another student stated about these applications that "I don't know if the lecturer has [social media] account". As a general notion there is likely to be plenty of variance here, some faculty members may actively use different social media applications, while others don't or they have them in personal use. When student would like to ask a question from the lecturer, it is asked by sending general mail-message or using internal mail-system provided by the Moodle platform. "Yes, I would simply send [standard] email". 
The range of applications used in courses varies, in different assignments and groups may different applications be used in contacting and interacting with fellow students and members in the same group or course. Basically, social media applications are used because they are considered flexible, versatile and intuitive. They are also easy to use directly from a smartphone, as there are applications for different smartphone operating systems. As noted by a student "I have access [to learning material and other group members] directly from my pocket".

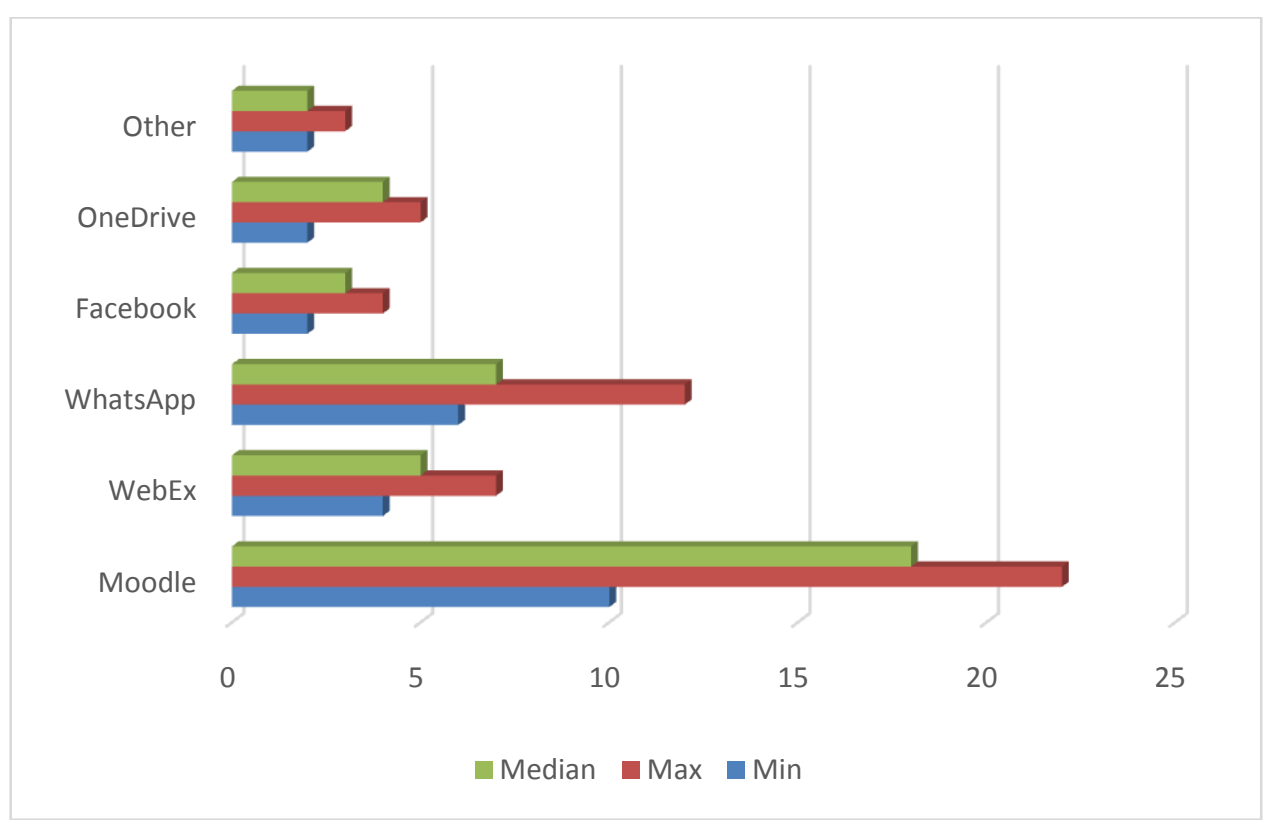

Figure 2: Popularity of different digital applications

The use of social media applications does not mean that official learning environment would be obsolete (Figure 2). It still provides learning material, exercises and timetable in a centralized location, and can be accessed from a distance. Social media applications provide additional flexibility, especially as they integrate to smartphones. This allows students to interact without the need to sit behind a desktop computer. Now interaction, group work and studying can literally take place anywhere and anytime. Therefore, social media applications can bring added value to learning environment.

The case university provides a learning platform with support for systems such as Moodle or WebEx. However, empirical results indicate that in group-based learning students tend to decide among themselves in groups what systems, applications and channels they use for collaboration. The findings suggest that there is room for tools and technologies that are part of the learning environment and applications come from outside the official learning platforms, mostly ones that are based on social media.

\section{Limitations and further research}

In this study the empirical data comes from one university, and the number of students participating in the research is limited. On the other hand, the main goal was to explore whether there were also other technologies in use than those 
officially supported by the university. This could be mapped already in this research.

For further research designs it would be interesting to extend the study to cover other universities. In the university where the empirical part was done there are pressures to integrate teaching resources among other universities. Therefore, in the future the research should be extended to include also these universities.

Another research area would be studying faculty members, especially those who are teaching. They have a critical role in selecting teaching methods, technologies and systems. Teachers should be included in further research activities, to ask about their views, experiences and motivations about current and future learning environments. This would give a wider perspective to developers of the learning environment, to be able to better help, guide and motivate teaching staff and learners. Furthermore, involvement of teachers would promote course development and use of different applications and technologies, that further empower students learning process.

\section{Discussion and conclusion}

Information systems and technologies are having an increasingly important role in learning environments. There is clearly a demand for education that makes it possible to combine work, family and school. While traditional education takes place primarily in classrooms, digital learning environments make it possible to study from a distance, regardless of time and space (Jonassen et al., 2008; Facer, 2011). Developers of digital learning environments should keep in mind that managing technology that is constantly changing requires the user to learn new skills (Burns, 2013). The learning environment should be easy to navigate, and it should address the needs of differently skilled students and their learning styles. Here using computers, networks and collaborative technologies are in a central role. It is also important that the learner can connect, interact and share with other learners, and participate actively as a member in a group (Laal \& Laal, 2012).

If we look at factors that hinder widespread use of technologies allowing digitalization of education, several potential barriers can be found (Burns, 2013; Moussa-Inaty, 2017). Even though the costs of technology have been going down there still may be issues with usability and interfaces. Combined with technological complexity and reliability especially those who are uncertain with technology or have limited skills, may have negative attitudes against learning environments which rely on information systems and technology. This does not mean that technology should not be blended with learning - and vice versa. Technology allows flexibility to study whenever and wherever as learning environments are being built to a website and can be accessed with a browser. Furthermore, there are plenty of modules and applications for communication and interaction, also various social media applications. Using these tools, people from different locations can study and work together. However, in formal teaching is the use of social media based applications relatively low. (Richmond et al., 2011) 
Interaction between teachers, students and student groups is important in the learning process (Leonard \& Leonard, 2001; Algozzine \& Anderson, 2007; Vass \& Littleton, 2010). With information systems and technologies this interaction can be empowered. The empirical evidence gathered in this study indicates that technology is used differently, it varies from course to course. While some courses can be relatively traditional with no technology involved, it is possible to find courses with a variety of technologies and applications. Different modules, tools and applications can give further flexibility in communications and interaction - whether they are part of the official learning environment or used on an ad hoc -basis. The choices on which communications channels and options to use depend on teachers and students, as revealed in this study.

The ability to use technologies and apply them to different situations is a valuable skill (Tomlinson, 2003; Burns, 2013). Learning material, courses and curriculum in general should allow different learners to use methods and pace that best fits their individual needs. In this view, there is room for both traditional and digital learning environments, as there are different learners. Clearly, digital learning environments provide opportunity to empower learners in the digital age (Jonassen et al., 2008).

\section{References}

Algozzine, B., \& Anderson, K. M. (2007). Differentiating instruction to include all students. Preventing School Failure: Alternative Education for Children and Youth, 51(3), 49-54. doi.org/10.3200/psfl.51.3.49-54

Brusilovsky, P. (2001). Adaptive Hypermedia. User Modeling and User-Adapted Interaction, $11,87-110$.

Burns, M. (2013). Success, Failure or "No Significant Difference": The Arguments For and Against Technology as a Learning Tool. International Journal of Emerging Technologies in Learning, 14(3), 38-45. doi.org/10.3991/ijet.v8i1.2376

Creswell, J. W. (2012). Educational research: Planning, conducting, and evaluating quantitative and qualitative research (4th ed.). Boston, MA: Pearson.

Dooley, C.M., Ellison, T.L., Welch, M.M., Allen, M. \& Bauer, D. (2016). Digital Participatory Pedagogy: Digital Participation as a Method for Technology Integration in Curriculum. Journal of Digital Learning in Teacher Education, Vol. 32, No. 2, 52-62. doi.org/10.1080/21532974.2016.1138912

Facer, K. (2011). Learning Futures. Education, technology and social change. London: Routledge. doi.org/10.4324/9780203817308

Gros, B. (2002). Knowledge Construction and Technology. Journal of Educational Multimedia and Hypermedia, 11(4), 323-343.

Hakkarainen, K. (2009). A knowledge-practice perspective on technology-mediated learning. International Journal of Computer Supported Collaborative Learning, 4(2), 213-231. doi.org/10.1007/s11412-009-9064-x

Harasim, L. (2012). Learning Theory and Online Technologies. Routledge Press, New York. doi.org/10.1111/teth.12071

Hummel, H., Manderveld, J., Tattersall, C., \& Koper, R. (2004). Educational modeling language and learning design: New opportunities for instructional reusability 
and personalized learning. International Journal of Learning Technology, 1(1), 111126. doi.org/10.1504/ijlt.2004.003685

Jonassen, D.H. (2000). Computers as Mindtools for Schools: Engaging Critical Thinking. Upper Saddle River, NJ: Merrill/Prentice Hall.

Jonassen, D.H., Howland, J., Marra, R.M. \& Crismond, D. (2008). Meaningful learning with technology, 3rd ed. Upper Saddle River, NJ: Pearson Merrill Prentice Hall.

Laal, M., \& Laal, Mo. (2012). Collaborative learning: what is it? Procedia - Social and Behavioral Sciences, 31, 491-495. doi.org/10.1016/j.sbspro.2011.12.092

Leonard, P. E., \& Leonard, L.J. (2001). The collaborative prescription: Remedy or reverie? International Journal of Leadership in Education, 4(4), 383-399. doi.org/10.1080/13603120110078016

Lim, C.P., \& Chai, C.S. (2008). Rethinking classroom-oriented instructional development models to mediate instructional planning in technology enhanced learning environments. Teaching and Teacher Education, 24(8), 2002-2013. doi.org/10.1016/j.tate.2008.05.004

Lim, D. H., Morris, M. L., \& Kupritz, V.W. (2014). Online vs. blended learning: Differences in instructional outcomes and learner satisfaction. Journal of Asynchronous Learning Networks, 11(2), 27-42.

Madge, C., Meek, J., Wellens, J. \& Hooley, T. (2009). Facebook, social integration and informal learning at university: 'It is more socialising and talking to friends about work than for actually doing work'. Learning, Media and Technology, 34(2), 141-155. doi.org/10.1080/17439880902923606

Mann, B. (2006). Selected Styles in Web-Based Educational Research. Hershey, PA: IGI Global. doi:10.4018/978-1-59140-732-4

Moussa-Inaty, J. (2017). Student Experiences of a Blended Learning Environment. International Journal of Learning, Teaching and Educational Research, 16(9), 60-72. doi.org/10.26803/ijlter.16.9.5

Pani, A.K., Srimannarayana, M., \& Premarajan, R.K. (2015). e-Learning: Challenges and Solutions - A Case Study. International Journal of Learning, Teaching and Educational Research, Special Issue, 13(4), 33-40.

Quan-Haase, A., \& Young, A. L. (2010). Uses and gratifications of social media: A comparison of facebook and instant messaging. Bulletin of Science, Technology $\mathcal{E}$ Society, 30(5), 350-361. doi:10.1177/0270467610380009

Raskin, J. (2000). The Human Interface, New Directions for Designing Interactive Systems. Addison-Wesley Longman Inc, Massachusetts.

Reeves, T.C., \& Laffey, J. (1999). Design, Assessment, and Evaluation of a Problem-based Learning Environment in Undergraduate Engineering. Higher Education Research \& Development, 18(2), 219-232. doi.org/10.1080/0729436990180205

Rich, E. (1998). User Modeling via Stereotypes. In Maybury, M.T., \& Wahlster, W. (Ed.) Readings in Intelligent User Interfaces. Morgan Kaufmann Publishers Inc, San Francisco, California.

Richmond, N.; Rochefort, B. \& Hitch, L.P. (2011). Using Social Networking Sites During the Career Management Process. In Wankel, L.A \& Wankel, C. (Ed.). Higher Education Administration with Social Media: Including Applications in Student Affairs, Enrolment Management, Alumni Affairs, and Career Centers. Bingley (UK): Emerald.

Tomlinson, C.A. (2003). Fulfilling the promise of the differentiated classroom. Alexandria, VA: Association for Supervision and Curriculum Development.

Vass, E., \& Littleton, K. (2010). Peer collaboration and learning. In Littleton, K., Wood, C., \& Staarman, J.K. (Ed.). International handbook of psychology in education. United Kingdom: Emerald, 105-136. 
Wagner, N., Hassanein, K., \& Head, M. (2008). Who is responsible for E-Learning Success in Higher Education? A Stakeholders' Analysis. Educational Technology \& Society, 11 (3), 26-36.

Wehner, F., \& Lorz, A. (2001). Developing Modular and Adaptable Courseware Using TeachML. Proceedings of ED-MEDIA 2001, 2013-201

White, C. P., Ramirez, R., Smith, J. G., \& Plonowski, L. (2010). Simultaneous delivery of a F2F course to on-campus and remote off-campus students. TechTrends, 54(4), 3440. https://doi.org/10.1007/s11528-010-0418-z 